\section{New guide for dentists to use social media safely}

The DDU (Dental Defence Union) has launched a new e-learning course designed to help dental professionals use social media ethically and effectively while also avoiding mistakes.

The Dento-legal aspects of using social media course includes fictional scenarios that are based on common queries and concerns that the DDU receives from members.

Topics covered include:

- Communication with patients and colleagues

- Marketing yourself using social media

- Relevant legal and ethical obligations.

The DDU said it had received positive feedback so far to the tool with participants commenting '[the tool is] extremely helpful and informative, particularly with real life scenarios and referring to GDC Standards' and 'easy to follow content, beautifully presented'

Leo Briggs, Deputy Head of the DDU said: 'Dental professionals have embraced social media and overall it is having a positive impact on dentistry by, for example, helping them to market their practice or giving patients access to more healthcare information from the profession itself. However, mistakes on social media, such as an inappropriate comment or photo, are easy to make and can damage your reputation and career.

'Consequently, the aim of this e-learning tool is to help dental professionals and students maximise the benefits of using social media and appreciate its pitfalls whilst continuing to meet ethical and legal obligations.'

Andrew Chandrapal, former President of the British Academy of Cosmetic Dentistry (BACD) and member of the DDU's Dental Advisory Committee said: 'Professional development is vital for dentists who wish to enjoy a long and rewarding career.

'The DDU's e-learning course enables dental professionals to promote their practice ethically on social media, understand the reputational risks associated with social media and how to respond appropriately to online complaints.'

The course is available at https://www. theddu.com/learn-and-develop/social-mediae-learning (accessed on 23 October 2018).

\title{
Poor access to urgent dental care pushing patients to GPs
}

Almost 400,000 people consult a GP with a dental problem every year due to poor access to urgent dental care, ignorance of services and fear of costly treatment, according to a recent study ${ }^{1}$ published on 23 October 2018 in the British Journal of General Practice (BJGP).

The study by researchers from University Dental Hospital in Cardiff concluded that dental problems need better coordinated care and many of these patients would be better treated by dental practitioners.

It is estimated that around 380,000 consultations per year in the UK in general practice are related to dental issues (just $0.3 \%$ of patients contacts for GPs) and overall consultation rates for dental problems in UK general practice fell between 2008-2013.

However, there is high variability between practices with rates up to 29.8 dental consultations per 1,000 patientyears in some practices.

The researchers, led by Dr Anwen Cope, specialty trainee and honorary lecturer in dental public health, Cardiff, and Vale University Health Board, University Dental Hospital, Cardiff, set out to explore why patients might consult a GP rather than a dentist when experiencing problems with their teeth or gums.

They carried out a qualitative, semistructured interview study with 39 adults who had consulted a UK GP with a dental problem in the previous 12 months.

Analysis of the interviews showed that patients were confused about the roles of dentists and GPs, but generally found the GP appointment system easier to negotiate then dentistry.

Many patients had had previous negative experiences of dental care, and some had dental phobias, making them more likely to consult a GP than a dentist.

The costs of dental treatment were also a deterrent to some patients.

The authors said: 'Consultations for dental problems in general practice are often not an effective or efficient use of resources. Patients are unlikely to receive the best care for their condition, leading to concerns about patient morbidity from untreated dental disease and the emergence and spread of antimicrobial resistance arising from inappropriate antibiotic prescribing.

'This study ... concludes that patients' consultation behaviour is not only influenced by their current symptoms and the relative availability and accessibility of general practice compared with dental care, but also by contextual factors such as past experiences of dental care and perceptions about scope of practice.'

The researchers recommended barriers to rapid consultations with dentists should be removed if possible, and that dental practitioners should provide timely access to urgent care, avoiding long waits during which patients might seek care from a GP instead.

General practice teams and dentists should provide 'signposting' for patients, explaining their respective roles, and how emergency dental services could be accessed, they added.

The BDA said patients with urgent dental problems typically required some form of operative intervention, which GPs were neither trained nor equipped to provide.

It estimated that the 380,000 GP consultations referenced in the study cost the NHS $£ 20.8$ million.

BDA's Chair of General Dental Practice, Henrik Overgaard-Nielsen, said: 'Dental patients face growing barriers, from higher charges to longer journeys, where even those entitled to free care face the everpresent threat of fines for misclaiming. The result is millions are being wasted, and pressure piled on overstretched GPs who are simply unequipped to help.

'Ministers need to end the hostile environment many patients face and ensure all those who need our care can access it.'

1. Cope A, Wood F, Francis N A, Chestnutt I G. Patients reasons for consulting a GP when experiencing a dental problem: a qualitative study. Br J Gen Pract 2018; DOI:10.3399/bjgp18X699749. https://doi. org/10.3399/bjgp18X699749. 